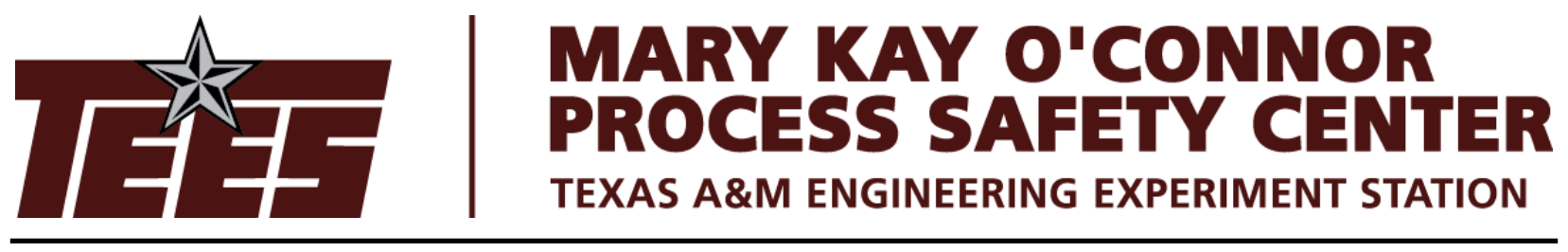

$22^{\text {nd }}$ Annual International Symposium

October 22-24, 2019 | College Station, Texas

\title{
Modelling Ice and Wax Formation in a Pipeline in the Arctic Environment
}

\author{
Ben Bbosa $^{\mathrm{b}}$, Zhengdong Cheng ${ }^{\mathrm{a}}$, Dali Huang ${ }^{\mathrm{c}}$, M. Sam Mannan ${ }^{\mathrm{a}}$, Michael Volk ${ }^{\mathrm{b}}$, \\ Hongfei $\mathrm{Xu}^{*} \mathrm{a}$ \\ a. Mary Kay O'Connor Process Safety Center,Artie McFerrin Department of Chemical \\ Engineering, Texas A\&M University System, College Station, Texas 77843-3122, USA \\ ${ }^{b}$. McDougall School of Petroleum Engineering, The University of Tulsa, Tulsa, Oklahoma \\ 74104, USA \\ c. Department of Materials Science and Engineering, Texas A\&M University, College Station, \\ TX, USA. \\ *Presenter E-mail: hongfeixu@ @amu.edu
}

\begin{abstract}
In the Arctic environment, fluid temperature in pipeline can drop below the freezing point of water, which causes wax and ice to form on pipeline surface. Solid formation on pipeline surface can lead to flow assurance and process safety issues, such as blockage of pipeline, pipeline component failure, and the release of hazardous liquid. The blockage of pipeline can cause additional burden or failure to pumping system. Remediating the plugging requires shutdown of pipeline operation, which cause tremendous cost and delay to the entire production system. Ice and wax deposition in pipeline is a slow process. Pigging operation can be used to remove the deposits on pipeline surface. However, if deposition is too thick, pipeline blockage can still occur. In order to prevent pipeline blockage, ice and wax deposition rates are required to be estimated. This paper investigates ice and wax deposition rates in a $90 \mathrm{~km}$ pipeline. A fundamental model for both ice and wax deposition is proposed using first principles of heat and mass transfer. The interaction between water and wax is analysed.
\end{abstract}

Keywords: Modeling, Two-Phase Flow, Ice and wax deposition, Pipeline plugging, Operations

\section{Introduction}

The Arctic is the region within approximately 66 degrees North parallel, including parts of Alaska (USA), Canada, Greenland (Denmark), Iceland, Sweden, Norway, Finland, and Russia (Johnstone, 2014). The existing fields beyond the rctic Circle account for $10 \%$ of the world's existing conventional resources (Gautier et al., 2009). The hydrocarbon potential of the Arctic region is 
considered as the final frontier for conventional hydrocarbon development. In oder to ensure contninuity in oil supply to global energy needs, oil companiesled to the oil and gas exploration and production activities in harsh environment including extremely low tempearutres (Kaiser et al., 2016).

Process safety and flow assurance challenges exsit due the harsh operating conditions in the Arctic (Khan et al., 2015). In addition to common flow assurance challenges, such as wax, hydrates, and corrosion issues, water or ice can also be a problem (Xu et al., 2018). In the low temperature conditions, even traceable amount of water in pipeline can cause ice formation, leading to pipeline blockages and associated risks. For example, It was reported that ice plugging deplayed the restart of the Poplar pipeline system gathering crude oil from Montana and North Dakota (Sunne, 2015). The potential risk of ice formation also draw the attention of Trans-Alyeska Pipeline Systems (TAPS) (Alyeska Low Flow Impact Study Team, 2011). The possible delining throughts in the pipeline can decrease its oil temperature below water freezing point. Ice formation can can lead to restruicting flow and plugging of pipeline, which can causes pump overburden or even failure. In addition, ice can also lead to temperature and pressure transducer failure. The remediation of a plug may be costly and can lead to environmental issues (Comfort et al., 2008; Huang et al., 2011).

We focuses on two flow assurance solids in this study, wax and ice. Wax deposition is an existing flow assurance issue for pipelines in a cold environment, such as the Arctic or subsea. Ice deposition is an potential issue for pipeline in the regions where environmental temperature can drop below water freezing point. When hot oil flows along the pipeline in cold regions, such as subsea and Arctic regions, heat is lost through the pipe wall to the cold environment. The decreasing oil temperature leads to the decreasing solbility of the heavier components in the bulk oil (Han et al., 2010). As a result, wax deposition may occur. A wax deposition model is to calculate the location and the growth rate of the wax layer. A variety of thoeries were proposed to describe the wax deposition process, including molecular diffusion, shear dispersion, Brownian diffusion and gravity settling (Burger et al., 1981). Experiments have shown that molecular diffusion is the main mechanism for wax deposition (Singh et al., 1999). In addition to the growth of wax deposition layer, wax molecule can diffuse within the deposition layer, increasing wax fraction in the deposition layer, which is so called "wax aging" (Aiyejina et al., 2011).

Modelling of ice formation and its deposition on a surface has been widely studied in meteorology, aviation, and the refrigeration industries (DeMott et al., 1983; Kim et al., 2014; Messinger, 1953; Myers \& Charpin, 2004; Niezgoda-Żelasko \& Zalewski, 2006a; Walker, 2002). In meteorology, depends on the environmental temperature and the state of water, hoar frost, rime, or glaze ice can form on a surface (Walker, 2002). Modeling the growth rate of one ice morphology needs to consider its forming conditions. For example, Hoar frost is due to the sublimation of water vapor on a surface, and thus molecular diffusion is the main forming mechanism. Other morphologies needs to take consider of water films on surface or droplets in the ice formation process. In aviation industry, aircraft icing can pose a serious threat to flight safety (Cooper et al., 1984). The modelling of aircraft icing considers air flow, water droplets trajecties, as well as surface growth mode (Myers \& Charpin, 2004). Although few published work studied ice formation in hydrocarbon flow lines, experimental and numberical simulation of ice slurry flow in pipe are widely reported in refrigeration industries (Grozdek et al., 2009). Models for ice slurry flow considers the factors such as composition of ice slurry, pipe shape, and concentraction (Chhabra \& Richardson, 2011; Niezgoda-Żelasko \& Zalewski, 2006b). 
The objective of this study to model ice and wax deposition in a liquid hydrocarbon and low water cut system. Molecular diffusion is assumed for the formation mechanism for wax deposition, ice deposition, and the deposition with wax and ice mixture. The interaction between ice and wax in the deposition are studied.

\section{Model Development}

2.1 List of assumptions

We adopt several common assumptions when modelling the velocity, heat exchanges, and wax and ice deposition. These include the following.

1) The oil behaves as a Newtonian fluid.

2) Molecule diffusion dominates the mass transfer of wax and water (ice) in both the bulk fluid and the deposits.

3) The formed deposition layer cannot be sloughed off by fluid shear.

4) Thermal conductivities of ice and wax are assumed to be constant, which are not function of temperature.

5) The environmental temperature is constant along the pipeline, not changing with geography.

6) The inlet fluid properties and flow rate remain unchanged.

The 2) assumption indicates in this study the growth of deposition is due to molecular diffusion, not by solid particle settlement. The precipitated wax particles stay in the bulk fluid. In addition, the water content in this study is extremely low. Only dissolved water in oil is considered. Deposition growth due to settlement of free water droplets and ice particles is ignored in this study.

\subsection{Governing equations}

In order to quantify the deposition rate, the transport euqaitons are solved first to obtain the velocity, temperature, and concentraciton profiles in the bulk fluid. Firstly, the velocity profile is obtained using the following analytical solutions for laminar flow and turbulent flow.

For laminar flow (i.e. Reynolds number (Re) smaller than 2000),

$$
v_{z}(r)=2 * v_{z, a v e} *\left(1-\left(\frac{r}{R}\right)^{2}\right)
$$

For turbulent flow, Re>2000 (Deen, 1998),

$$
v_{z}=v_{z}^{+} * \sqrt{\frac{\tau_{w}}{\rho}}=v_{z}^{+} *\left(y^{+} * \frac{v}{y}\right)
$$

where $v_{z}^{+}, y^{+}, f$ and $v$ are defined as follows.

$$
v_{z}^{+}=\left\{\begin{array}{cc}
y^{+} & y^{+} \leq 5 \\
5 \ln y^{+}-3.05 & 5 \leq y^{+} \leq 30 \\
2.5 \ln y^{+}+5.5 & 30 \leq y^{+}
\end{array}\right.
$$




$$
\begin{gathered}
y^{+}=\frac{y}{v} \sqrt{\frac{\tau_{w}}{\rho}}=\left(1-\frac{r}{R}\right) \frac{R e}{2} \sqrt{\frac{f}{8}} \\
f=\frac{0.305}{R e^{0.25}} \\
v=\frac{\mu}{\rho}
\end{gathered}
$$

A backward implicit numerical scheme is used to solve the heat and mass transfer equations, which can give a stable solution (Pletcher et al., 2012). The heat and mass transfer equations are expresses as follows

(Heat transfer)

(Mass transfer)

$$
v_{z} \frac{\partial T}{\partial z}=\frac{1}{r} \frac{\partial}{\partial r}\left[r\left(\varepsilon_{H}+\alpha_{T}\right) \frac{\partial C}{\partial r}\right]
$$

$$
v_{z} \frac{\partial C}{\partial z}=\frac{1}{r} \frac{\partial}{\partial r}\left[r\left(\varepsilon_{M}+D_{w o}\right) \frac{\partial C}{\partial r}\right]-k_{r}\left(C-C_{w s}\right)
$$

where for laminar flow, $\varepsilon_{\mathrm{H}}=\varepsilon_{M}=0$. For turbulent flow the momentum thermal and mass diffusivities can be obtained using the following correlations.

$$
\begin{aligned}
\varepsilon_{\mathrm{H}} & =\alpha_{T} * \frac{P r}{P r_{T}} * \frac{\varepsilon}{v} \\
\varepsilon_{\mathrm{M}} & =D_{w o} * \frac{S c}{S c_{T}} * \frac{\varepsilon}{v} \\
P r_{T} & =0.85+\frac{0.015}{P r}
\end{aligned}
$$

The relationship between eddy momentum diffisvity, $\varepsilon$, and dynamic viscosity, $v$ is obtained using the correlations of Van Driest (1956):

$$
\frac{\varepsilon}{v}=\left(k y^{+}\right)\left[1-\exp \left(-\frac{y^{+}}{A}\right)\right]^{2}\left|\frac{d v_{z}^{+}}{d y^{+}}\right|
$$

Rate of wax precipitation is expressed using first order reaction, $k_{r}\left(C-C_{w s}\right)$ (Huang et al., 2011). The reaction constant $k_{r}$ is an empirical term, which can be obtained using:

$$
\begin{aligned}
k_{r}(T)=k_{r} & (\text { WAT or freezing } T) *\left(\frac{T}{\text { WAT or freezing } T}\right)^{1.47} \\
& * \exp \left(\frac{\gamma E}{R}\left(\frac{1}{T}-\frac{1}{\text { WAT or freezing } T}\right)\right)
\end{aligned}
$$


where $k_{r}$ is precipitation rate constant of wax or ice in oil and $E$ is activation energy. Both $k_{r}$ and $E$ can be obtained through experiments. In this study, $k_{r}$ uses value of 1.4 and $E=37700 . \gamma$ is obtained using the following correlation.

$$
\gamma=\frac{10.2}{V_{M}}-0.791
$$

The boundary conditions for eqn. 7 and eqn. 8 are given as follows.

$$
\begin{gathered}
\left\{\begin{array}{cc}
T=T_{\text {inlet }, \text { oil }} & \text { at } z=0 \\
\frac{\partial T}{\partial r}=0 & \text { at } r=0 \\
h_{o}\left(T_{\text {out }}-T_{\text {wall }}\right)=k_{\text {dep }} \frac{\partial T}{\partial r} & \text { at } r=r_{\text {eff }}
\end{array}\right. \\
\left\{\begin{array}{cc}
C=C_{\text {inlet }, \text { oil }} & \text { at } z=0 \\
\frac{\partial C}{\partial r}=0 & \text { at } r=0 \\
C=C_{w s}(T) & \text { at } r_{\text {eff }} \leq r \leq r_{\text {inner radius }}
\end{array}\right.
\end{gathered}
$$

where $r_{e f f}$ is effective flowing diameter, which is the radius from the pipe centreline to the deposition surface. $C_{w s}(T)$ is concentration obtained from solubity curve, which means in the deposit, wax or ice concentraction follows liquid/solid ebuiliburm.

\subsection{Deposition model}

Molecular diffusion is assumed to be the deposition mechanism. Molecular diffusion occurs not only in the bulk but also in the depsotion layer. Wax or ice deposits have a porous structure with entroppaed liquid providing a pathway fo the diffusion of wax molecule within the deposit. Along the radial direction, the mass flux of wax molecules or water molecules first diffuse from the bulk to the deposition interface. Then, a second diffusion exists in the porous deposition, increasing the solid concentraction in the deposit, which is called aging phenomena. The deposition growth takes account of the flux in the bulk and the flux within the deposit, which is expressed as:

$$
\begin{aligned}
& \rho_{g e l} F_{\text {wax }} \frac{d\left(\delta_{\text {deposit }}\right)}{\partial t}=J_{\text {bulk to interface }}-J_{\text {within the deposit }} \\
& J_{\text {bulk to interface }}=-D_{w o_{w a x}} \frac{d C_{w s}}{\partial r} \mid \begin{array}{c}
\text { from oil } \\
\text { to interface }
\end{array} \\
& J_{\text {within the deposit }}=-\left.D_{\text {eff_wax }} \frac{d C_{w s}}{\partial r}\right|_{\text {from interface }}
\end{aligned}
$$

Mass balance over the deposit can be expressed as: 


$$
\begin{gathered}
\pi \rho_{g e l}\left(R^{2}-r_{e f f}^{2}\right) \frac{d\left(F_{w a x}\right)}{\partial t}=-2 \pi r_{e f f} * J_{\text {within the deposit }} \\
r_{\text {eff }}=r_{i}-\delta_{\text {deposit }}
\end{gathered}
$$

Within the porouse deposit, the existence of solid phase provides mass transfer resistance. To take account of the effect of solid phase on mass transfer, an effective diffusion coefficient is used in eqn 17, (Aris, 1985) which is defined as:

$$
D_{e f f \_w a x}=\frac{D_{w o \_w a x}}{1+\frac{\alpha^{2} F_{w a x}^{2}}{1-F_{w a x}}}
$$

where $\alpha$ is aspec ratio, which is related to wax concentraction, $F_{\text {wax }}$.

\subsection{Meshing}

We discretise the 2-D cylindrical pipeline (eqn 7 and 8) with finite difference method. In vertical direction, a constant grid block size is used because uniform environmental properties are assumed. The grid blocks in radial direction are logarithmically distributed, with finer meshes near the pipe wall region:

$$
r_{i}=\left(r_{e f f} * \frac{\log (i)}{\log \left(\text { num }_{R}\right)}\right)^{0.4}
$$

Since the effective flowing diameter decreases when deposition occurs. The mesh in radial direction is updated for each time step.

\section{Materials}

If temperature in a pipline varies significantly, fluid viscosity and density can no longer be assumed as constant along the pipeline. Instead, we use viscosity function and density function to describe their relationships with temperature. In this study, we use the properties of TAPS crude oil. The density and viscosity are measured using using a Stabinger Viscometer (Anton Paar, SVMTM 3000). The obtained density and viscosity relationships with tempearutre are expressed as:

$$
\begin{gathered}
\rho\left(\frac{g}{c m^{3}}\right)=0.877-0.00428 *\left[T\left({ }^{\circ} C\right) * \frac{5}{9}+32\right] \\
\mu(c p)=\exp \left(\exp \left[36.409-5.6959 * \log \left(T * \frac{5}{9}+32+460\right)\right]\right)
\end{gathered}
$$

Commercial software PVTSim is used to obtain the wax solubility and water solubitliy. Figure 1 shows the the wax solubility curve. Figure 2 the water solubility curve. 


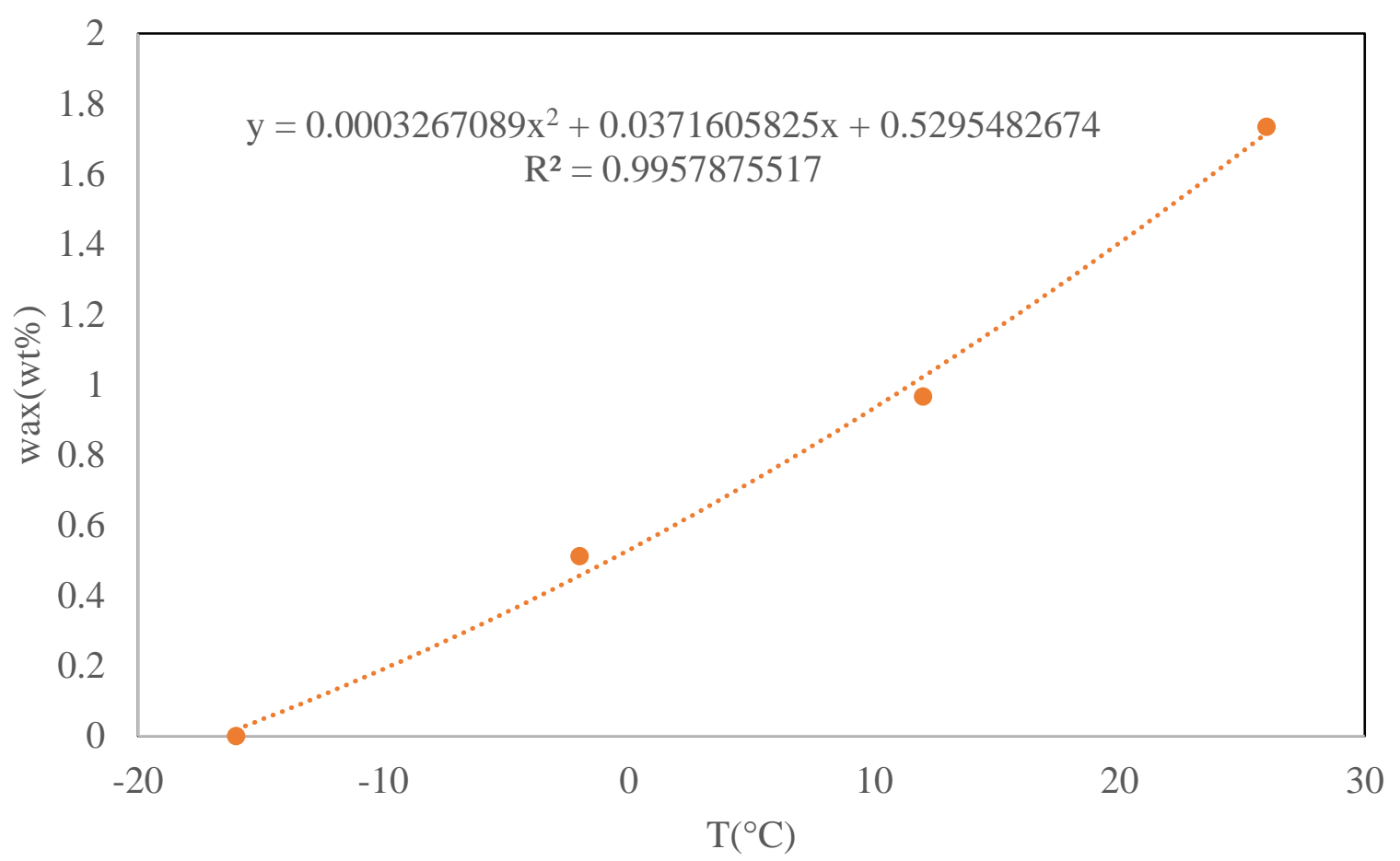

Figure 1: Wax solubility in TAPS oil

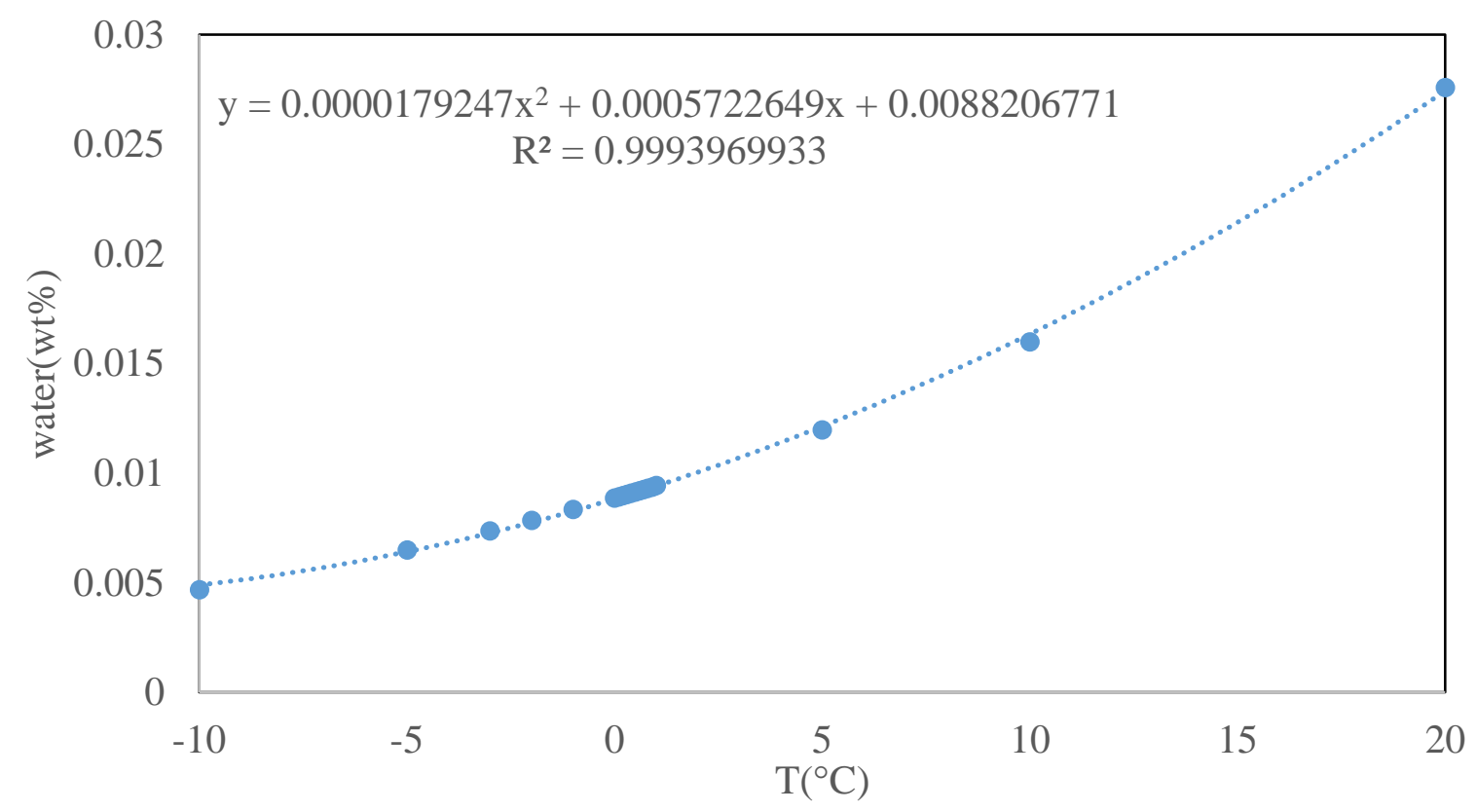

Figure 2: Water solubility in TAPS

\section{Results and discussion}

As oil enters the pipeline, its temperature decreases due to heat loss to the environment. When fluid temperature drops below WAT, wax precipitation occurs. Near the pipe wall region, if the 
pipe wall temperature is below WAT, wax deposition may occur. If the oil travelles further along the pipeline with more heat losses, its temperature can drop below freeing point of water. At these locations, the deposition is a mixture of wax and ice.

In this section, we first conduct a numerical convergence study to determine the optimal discretization of numerical models. Then, we show deposition growth and aging in the case of wax deposition without ice deposition, followed by the case of ice deposition without wax deposition. Finally, a cominbed deposition case is studied to show the interaction of ice and wax in the deposition process. Table 1 shows the pipeline geometry and thermal properties of pipeline and deposits in this study.

Table 1: Pipeline geometry and thermal properties of pipeline and deposits in this study

\begin{tabular}{lll}
\hline Parameter & Value & Units \\
\hline Pipeline length & 90000 & $\mathrm{~m}$ \\
Inner diameter & 0.5 & $\mathrm{~m}$ \\
Pipe thickness & 0.012 & $\mathrm{~m}$ \\
Insulation thickness & 0.1 & $\mathrm{~m}$ \\
Thermal conductivity of ice & 2.22 & $\mathrm{~W} /(\mathrm{m} \cdot \mathrm{K})$ \\
Thermal conductivity of wax & 0.25 & $\mathrm{~W} /(\mathrm{m} \cdot \mathrm{K})$ \\
Water freezing point & 0 & ${ }^{\circ} \mathrm{C}$ \\
Wax apperance temperature & 24 & ${ }^{\circ} \mathrm{C}$ \\
Intial solid fraction for wax or ice & 0.05 & \\
Environmental temperature, $T_{\text {environment }}$ & -7 & ${ }^{\circ} \mathrm{C}$ \\
Inlet temperature of fluid, $T_{\text {in }}$ & 25.5 & ${ }^{\circ} \mathrm{C}$ \\
Outside conductive heat transfer coefficient, $h_{o}$ & 5 & $\mathrm{~W} /\left(\mathrm{m}^{2} \cdot \mathrm{K}\right)$ \\
Oil inlet flow rate & 76.72 & $\mathrm{Mbbl} / \mathrm{D}$ \\
Simulation time & 336 & $\mathrm{hours}$ \\
\hline
\end{tabular}

\subsection{Nuemerical convergence study}

In this section, a numerical convergence study is conducted to determine the optimal discretization of numerical models. Deposition is not considered in this part of study. Firstly, we campare the bulk temperature, interface temperature, interface concentraction using different block number, num- $\mathrm{Li}$, in the axial direction, as shown in Figure 3. As number of blocks increased in the axial direction, the numerical solutions tends to converge. At the pipeline outlet, bulk temperatures are $-3.04,-3.34,-3.44{ }^{\circ} \mathrm{C}$ for num- $\mathrm{Li}$ equals to 1000,3000 , and 9000 respectively. We apply num$L i=9000$ for the discretization in the axial direaction. 

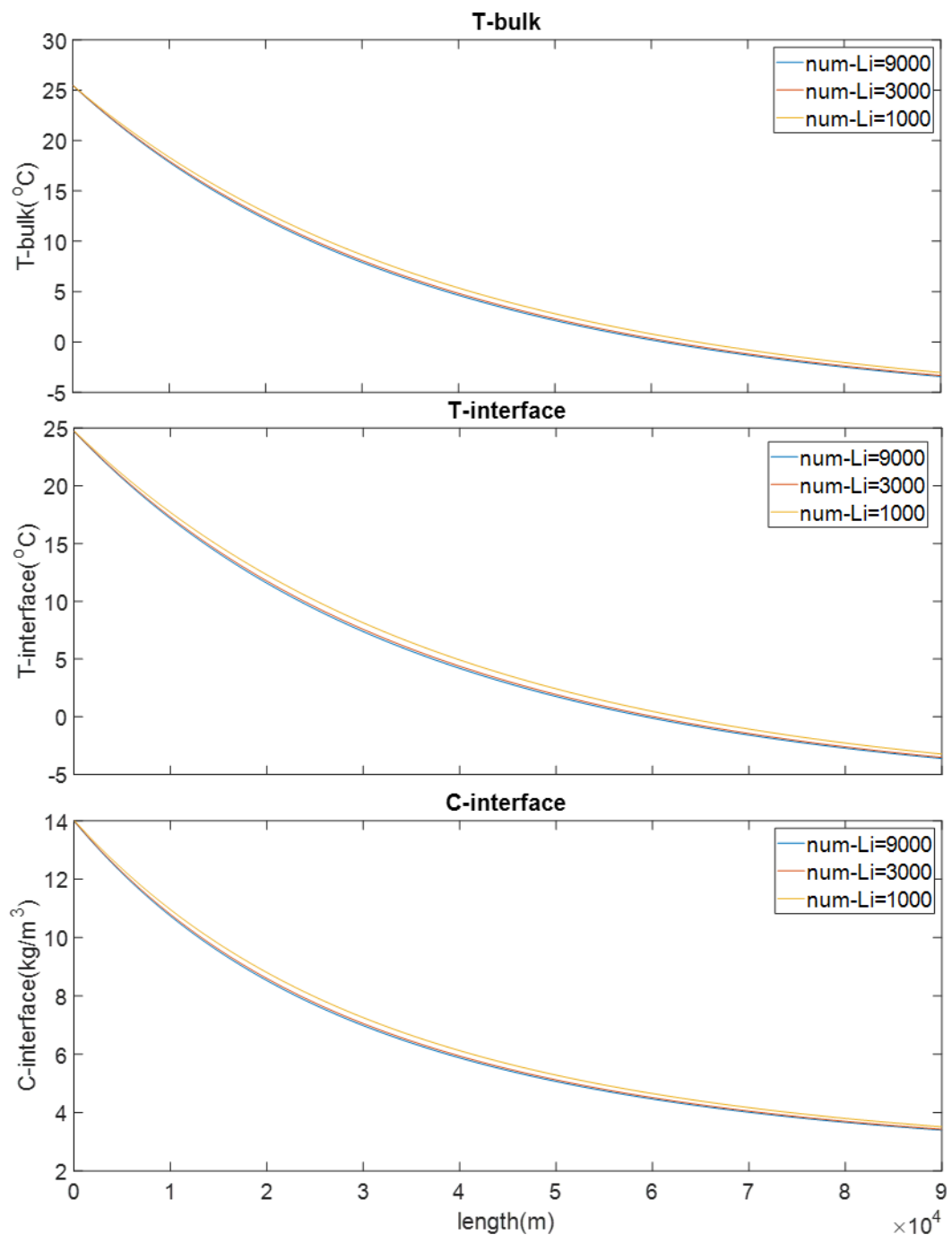

Figure 3: Comparison of bulk temperature, interface temperature, and interface wax concentraction with axial block number equals to 1000, 3000, and 9000

We campare the temperature profiles and concentraction profiles for num $_{R}$ equals to 50, 100, 200, and 400 at 15000, 30000, 60000, and 90000 m, which are shown in Figure 4 and Figure 5. With increasing block number, the temperature and concnetraction tends to converge. This is consistent with the observations of Li et al. (2012), which stated that the cylindrical coordinate requires a large number of grid blocks to obtain a grid-independent solution in heat conduction problem. To achieve a relative accurate solution, $\mathrm{nr}=200$ is used for the discretization in radial direction. 

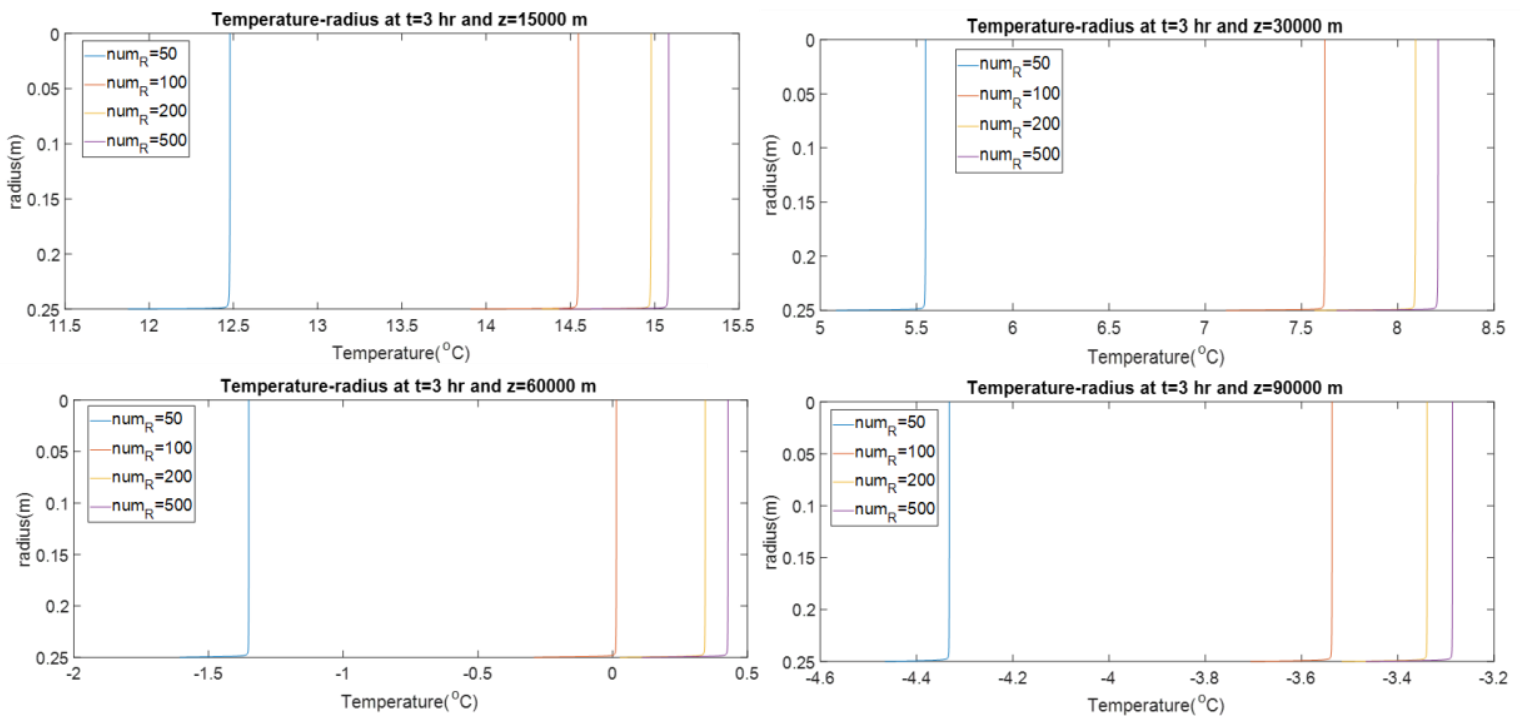

Figure 4: Comparison of temperature profile at 15000, 30000, 60000, and $90000 \mathrm{~m}$ with radial block number equals to 50, 100, 200, and 500
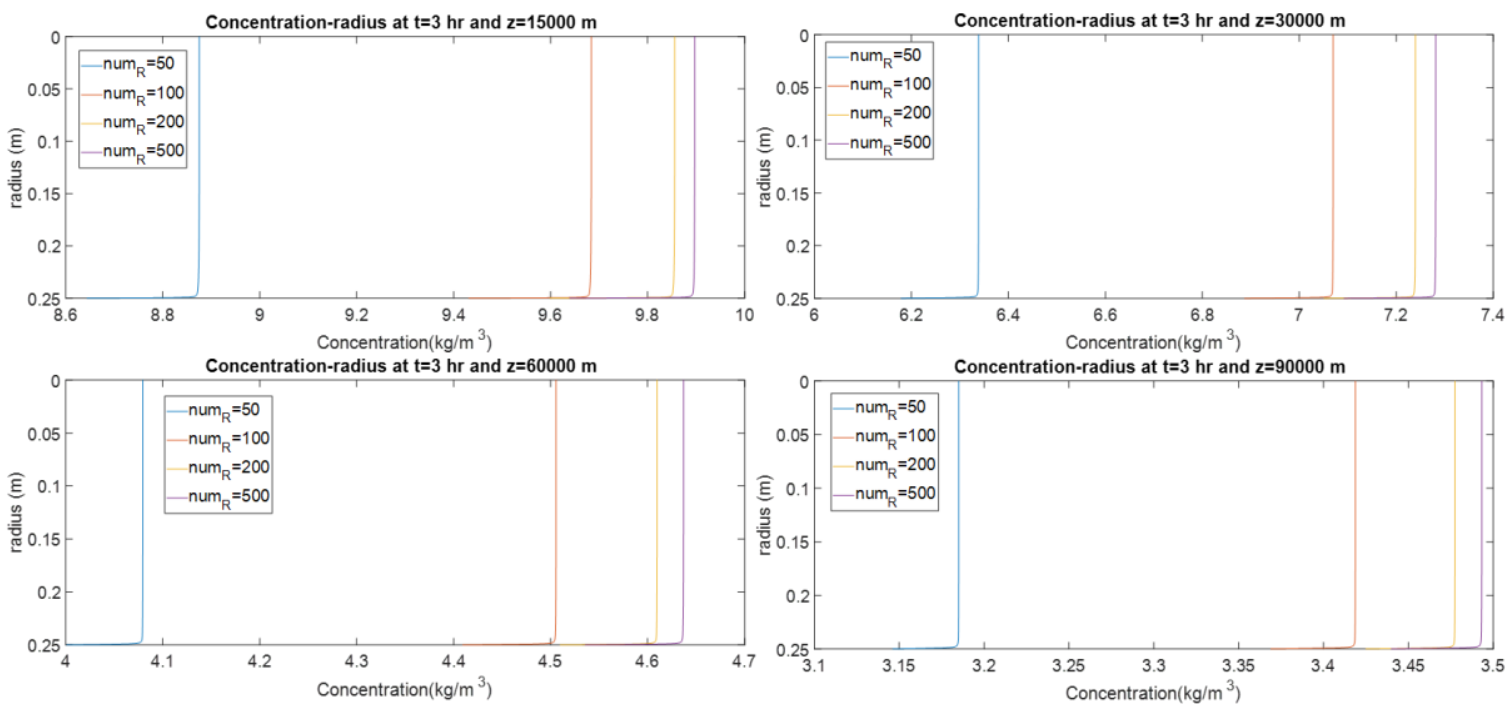

Figure 5: Comparison of concentration profile at 15000, 30000, 60000, and $90000 \mathrm{~m}$ with radial block number equals to $50,100,200$, and 500

\subsection{Case I:wax deposition}

Figure 6 shows the axial profile of the predicted deposit thickness in the deposit. Three sections exist in the deposit profile, including no deposition, significant deposition, and insignificant deposition. In the no deposition zone $(0-1.3 \mathrm{~km})$, the inner wall temperature is higher than wax appearance temperature. In the second section, the significant deposition zone, inner wall temperature drops below the WAT, which means wax molecules start to deposit in this section. A significant wax build up is observed in this section. In addition, wax deposition works as an insulation layer, reducing heat loss to the environment. Thus, the interface temperature increases as time passes by. For the loations where the interface temperature that is below WAT increase above WAT, wax deposition stops. In other words, as time passes by, the location where wax start 
to deposit moves to a downstream location. In the third section, due to the decrease of bulk temperature, riadial thermal gradient in the oil decreases. The driving force for wax deposition, which is the difference between bulk concentraction and interface concentration, decreases. Thus, deposition in this section is insignificant.
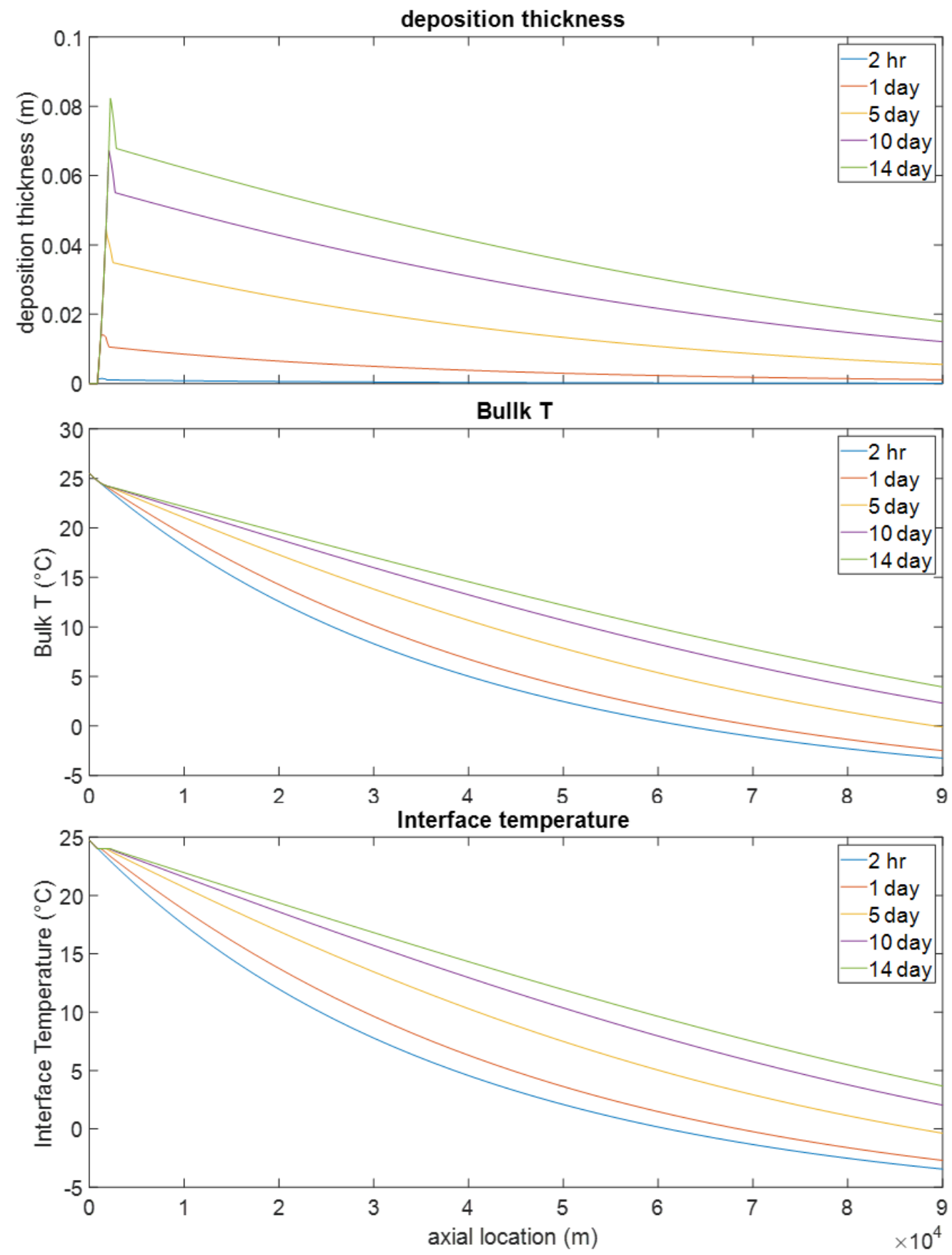

Figure 6: Prediction of the wax deposition thickness, bulk temperature, and interface temperature along the pipe at 2 hours, 1 day, 5 days, 10 days and 14 days 
Figure 7 shows the axial profile of the predicted wax fraction in the deposit. Similar to the thickness profile, the wax fraction has a maximum at the location where the driving force for aging reaches its maximum.

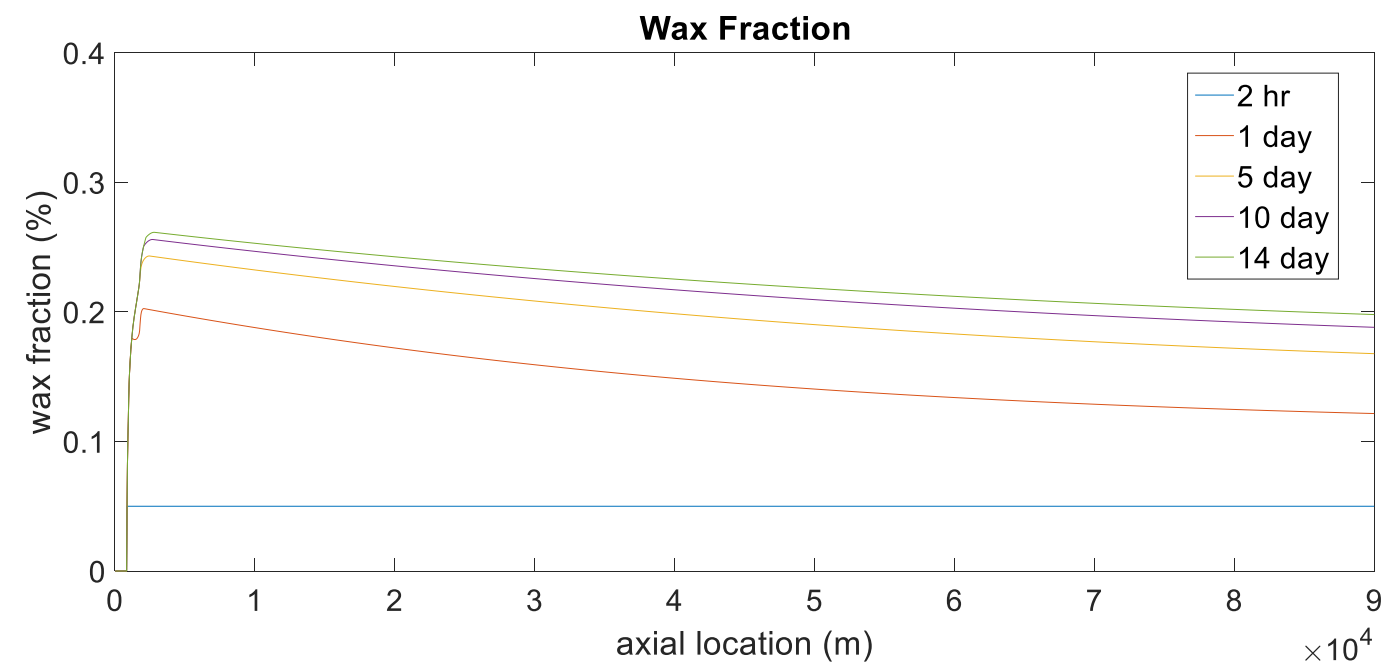

Figure 7: Prediction of the wax fraction along the pipe at 2 hours, 1 day, 5 days, 10 days and 14 days

\subsection{Case II: Ice deposition}

If the interface temperature drops below water freezing point, ice may form. In the second case of this study, we assume wax deposition does not occure and only ice deposition occurs in the pipeline. Figure 8 shows the ice depsoiton thickness, along with the interface temperature and bulk temperature. Similar to the case of wax deposition, three sections exist in the deposition profile. In the no deposition zone, the inner wall termpature is higher than the water freezing point and thus no ice deposition is observed in this section. In the significant depsotion zone, where the driving force for ice deposition is high, the ice buildup has a mixumum in this section. In the insignificant deposition zone, ice deposition is insignificant.

By comparing with Case 1, it is found that the ice deposition rate is smaller than wax deposition rate. This is due to the smaller driving force for ice depsotion. The water concentraction and concentraction gradient are smaller than wax concentraiton and concnetration gradient. The bulk fluid temperature and interface temperature do not have a significant change compared with the wax deposition case. In the ice depsotion case, the deposition thickness is smaller than that of wax. In addition, thermal conductivity of ice is larger than that of wax $(2.22 \mathrm{~W} /(\mathrm{m} \bullet \mathrm{K})$ for ice and $0.25 \mathrm{~W} /(\mathrm{m} \bullet \mathrm{K})$ for wax $)$. Thus, the heat loss in the ice deposition case is faster than the one in the wax deposition case. 

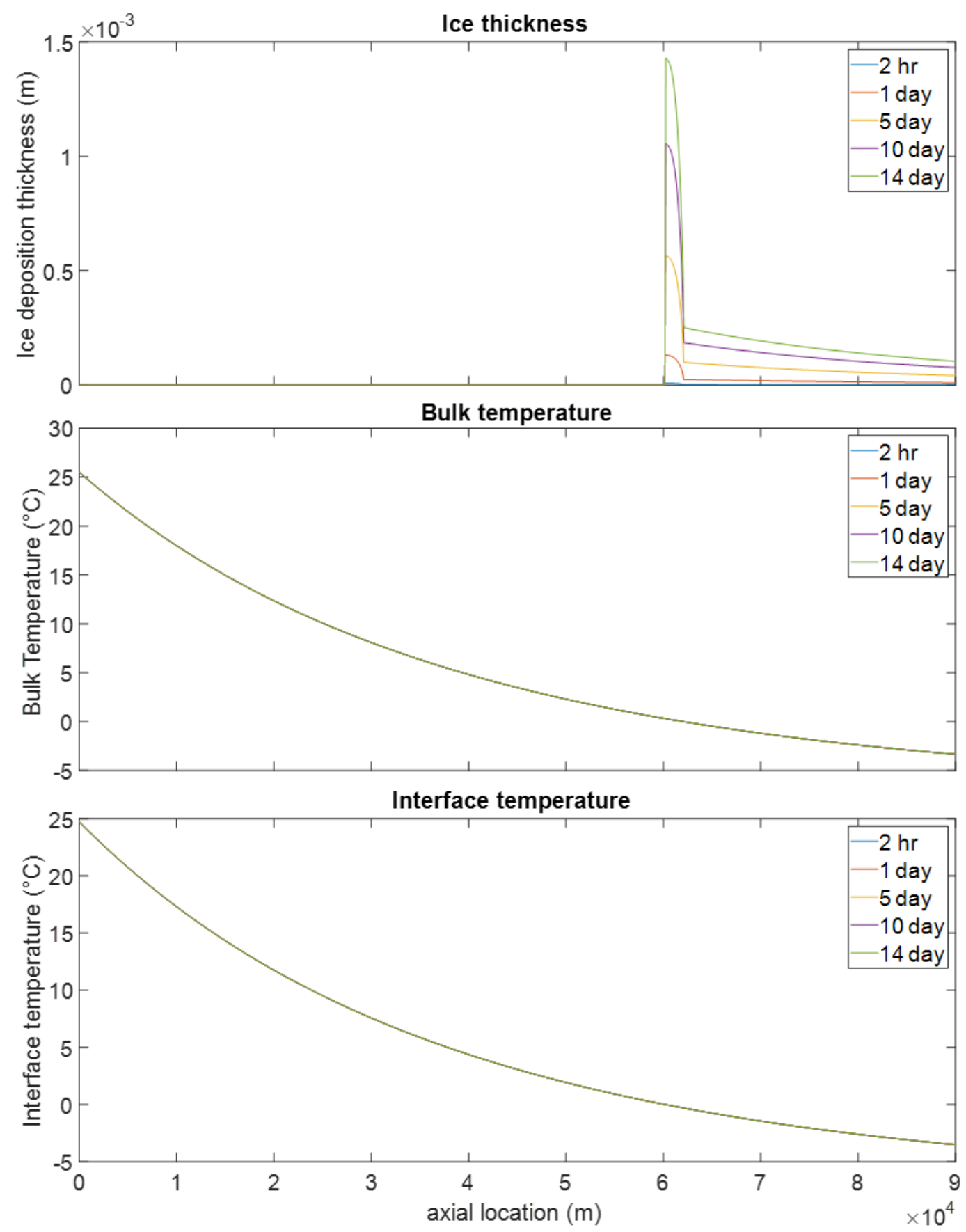

Figure 8: Prediction of the ice deposition thickness, bulk temperature, and interface temperature along the pipe at 2 hours, 1 day, 5 days, 10 days and 14 days

Figure 9 shows the axial profile of the predicted ice fraction in the deposit. Similar to the thickness profile, the ice fraction has a maximum at the location where the driving force for aging reaches its maximum. 


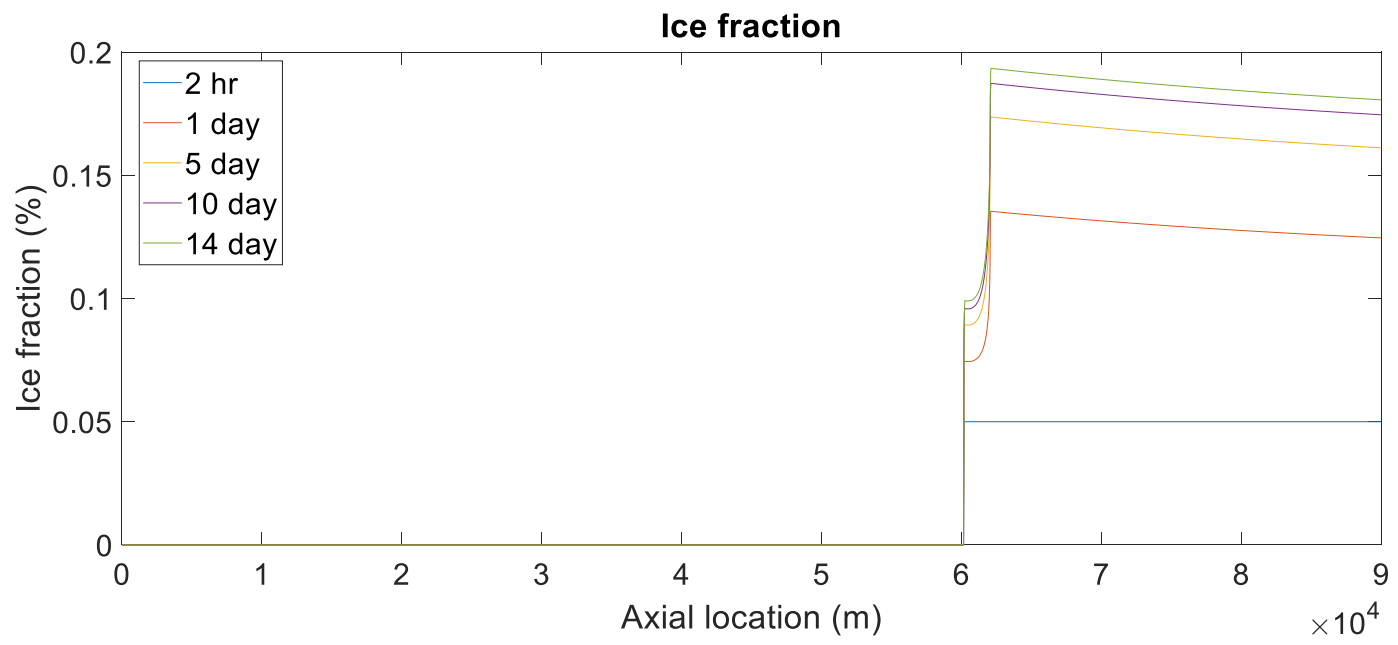

Figure 9: Prediction of the ice fraction in the ice depsotion along the pipe at 2 hours, 1 day, 5 days, 10 days and 14 days

\subsection{Case III: Wax-ice deposition}

As oil travelled along pipeline, its temperature drops due to the heat exchange to the environment. If the fluid temperauter is below WAT but above the water freezing point, only wax depoiston occurs. If the oil travelled further and its temperature dropped below the water freezing point, both wax deposition and ice deposition occur. The interaction between these two solids exists in both the bulk fluid and deposition. To similfy the study, we assumed no ice particles in the bulk fluid due to the low concentration of water in this study. Similarly, it is assumed that wax particles do not have effects on water diffusions in the bulk. In the deposition, wax diffusion competes with water diffusion. The existence of either solid works as barriers for both wax and water diffusion in the deposition. In addition, the thermal conductivity of the deposit needs to consider the coexistence of wax and ice in the deposition.

Figure 10 shows the the axial profile of the predicted deposit thicknes, as well as the interface temperature and bulk temperature. Figure 11 shows the axial profile of the predicted wax deposition thickness, ice deposition thickness and total deposition thickness in the deposit. The total deposit thickness is the summation of wax deposition thickness and ice deposition thickness. 
Total deposition thickness
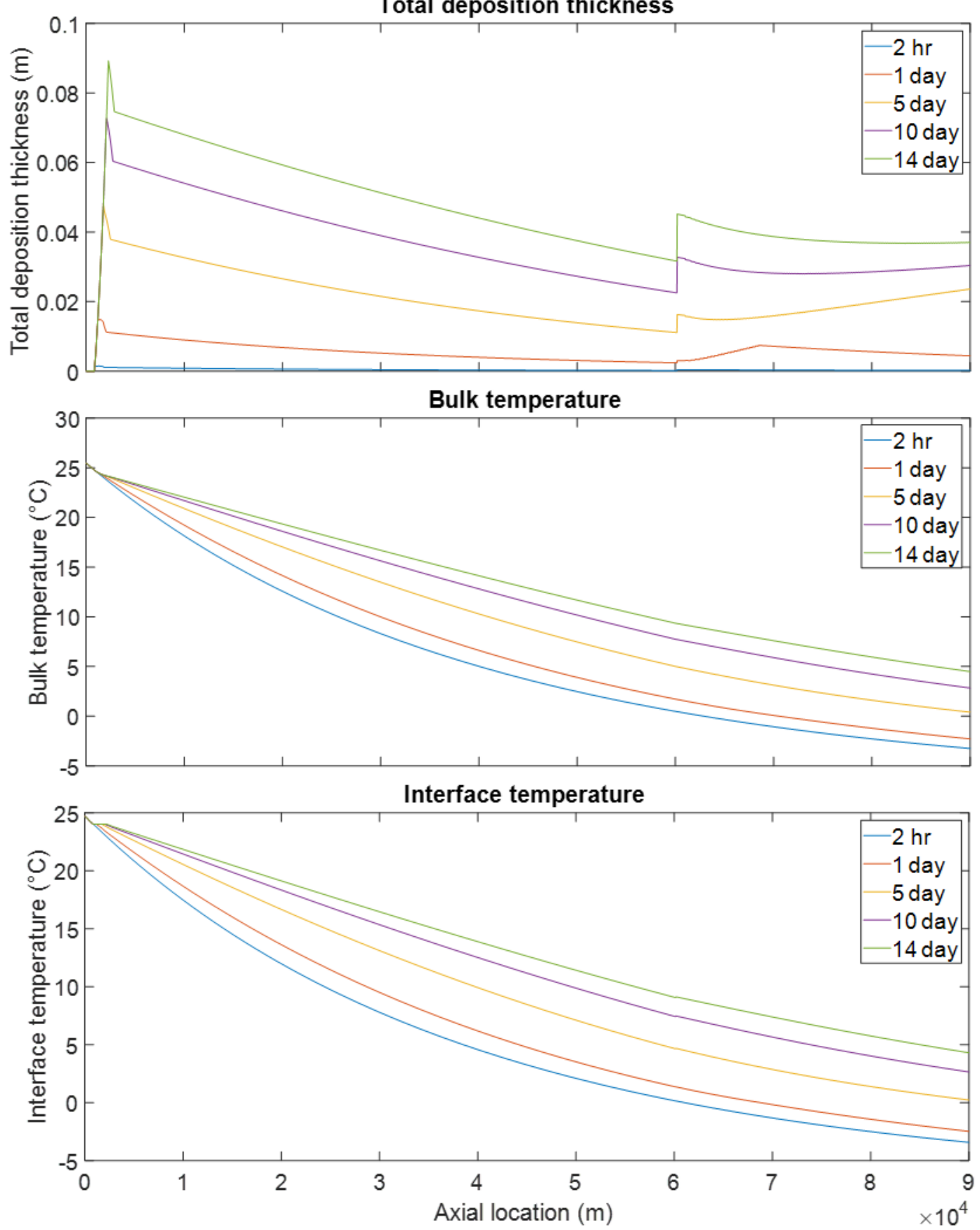

Figure 10: Prediction of the total deposition thickness, bulk temperature, and interface temperature along the pipe at 2 hours, 1 day, 5 days, 10 days and 14 days

Five sections exist in the deposition profile, including 1) no deposition, 2) significant wax deposition without ice depsotion, 3) insignificant wax deposition without ice depsotion, 4) significant ice depsotion in addition to wax deposition, and 5) insignificant ice deposition in addition to wax deposition. In the no deposition zone, the inner wall temperature is higher than wax appearance temperature. As fluid travels along the pipline with more heat loss to the environment, inner wall temperature dropes below wax appearance temperature but higher than 
water freezing point, which indicates only wax deposition occurs. Section with sifnificatn wax deposition is first observed, followed by section with insignificant wax deposition. The deposition thickness and aging in the deposit are similar to those studied in Case I.
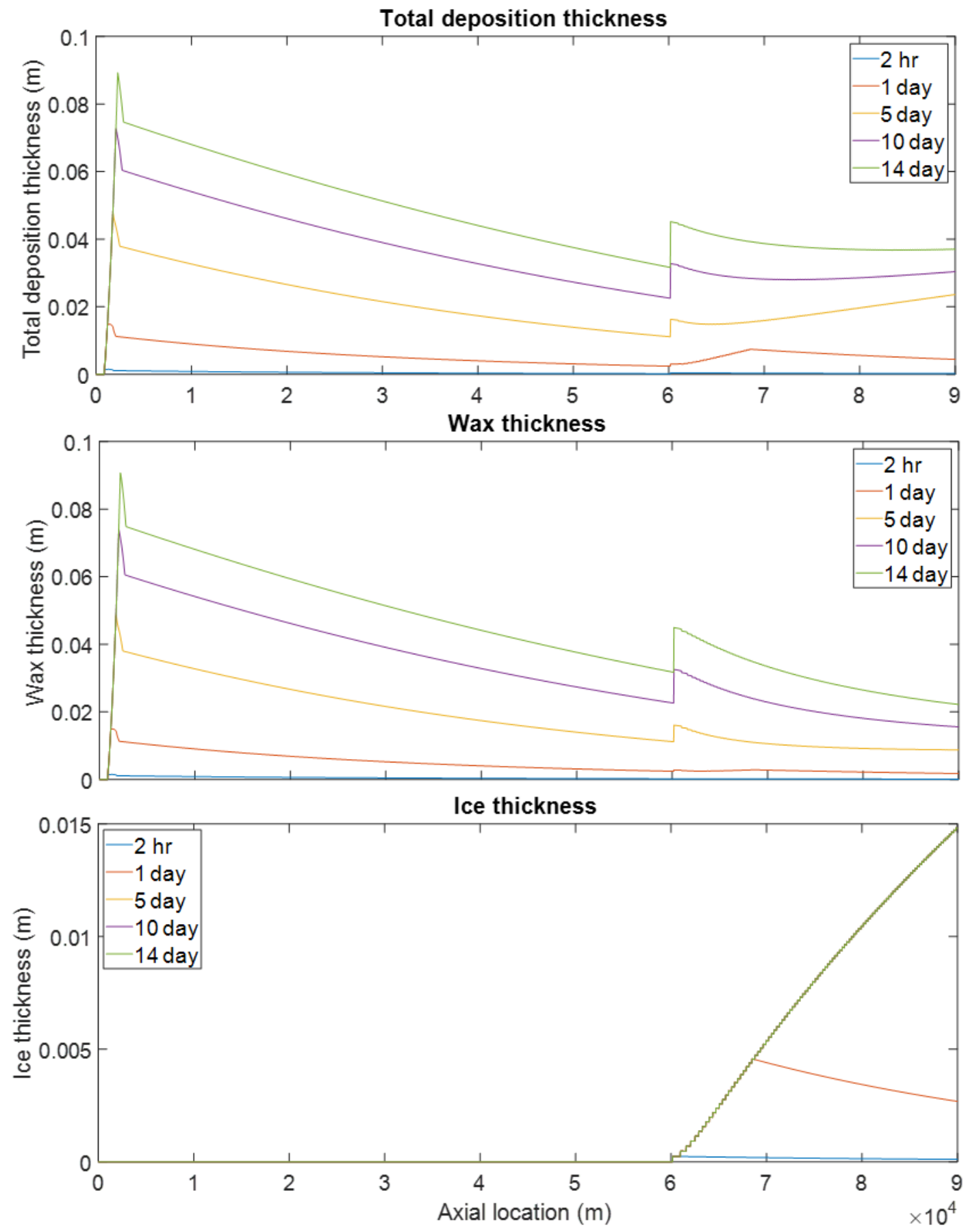

Figure 11: Prediction of the total deposition thickness, wax deposition thickness and ice deposition thickness along the pipe at 2 hours, 1 day, 5 days, 10 days and 14 days 
As the fluid travels further entering the fourth zone, its temperature can drops below ice freezing point, which can cause ice depsotion in addition to wax deposition. In the fourth section, significant ice deposition is observed. Unlike the ice depsotion in Case II, the competion between wax diffusion and water diffusion in the deposit, causes the ice fraction to be smaller, indicating the amount of water molecule diffused into the deposit is smaller. The decreased inner diffusion rate causes more water molucles to stay at the deposition interface, contributing to a larger ice depsotion thickness. Similarly, the decreasing inner wax diffusion rate causes a smaller wax fraction in the deposition and larger wax depsotion thickness than the ones in Case I.

Similar to Case I, the formed wax deposition along the pipeline decreased the heat loss to the environment, resulting in the increase of interface temperature and bulk tempture with time. Thus, at different times, the starting points for either wax deposition or the ice depsotion change to a further locations downstream. Especially for ice deposition, after day 5, the interface temperature along the pipeline is above water freezing point, resulting in no further ice formation. Thus, the ice thickness remained unchanged after day 5.

Figure 12 shows prediction of the total solid fraction, wax fraction and ice fraction along the pipe at 2 hours, 1 day, 5 days, 10 days and 14 days. In the zone that only have wax deposition, the total solid fraction is equal to wax fraction. In this case, it is similar to Case I. When ice start to deposit, the solid fraction is the summation of wax fraction and ice fraction in the deposit. The existence of the two solids in the deposit poses barriers for internal diffusion in the deposite. The aspect ratio in the section with both ice and wax formation is larger than the cases with only wax deposition or ice deposition. Thus, both wax and ice fractions in the deposit do not increase as fast as the one in Case I or II. Due to the decreasing internal diffusion in the deposit, the growth rate, which is the difference of bulk diffusion rate and internal diffusion rate increased in the section that has both wax and ice deposition. 
Total solid fraction

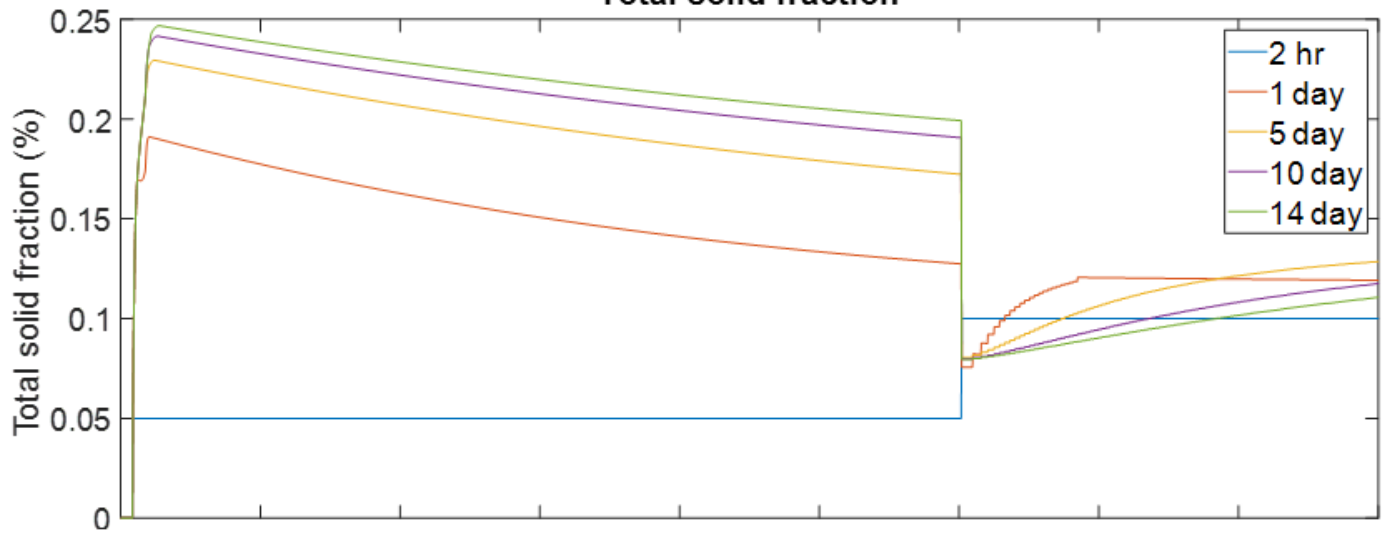

Wax fraction in depsit

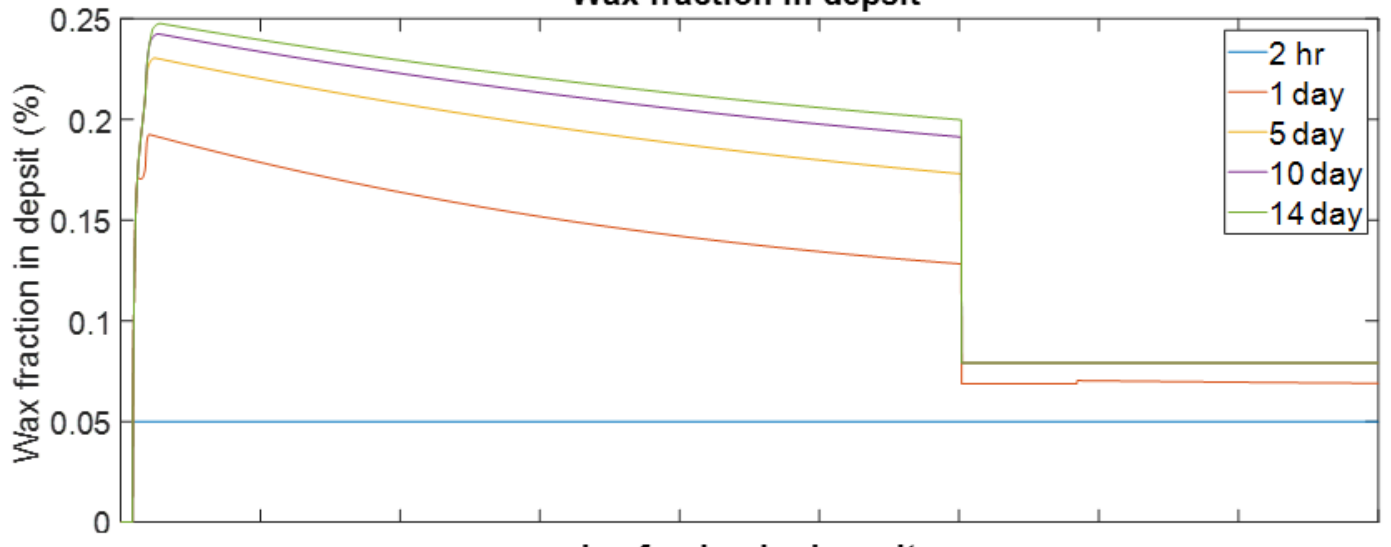

Ice fracion in deposit

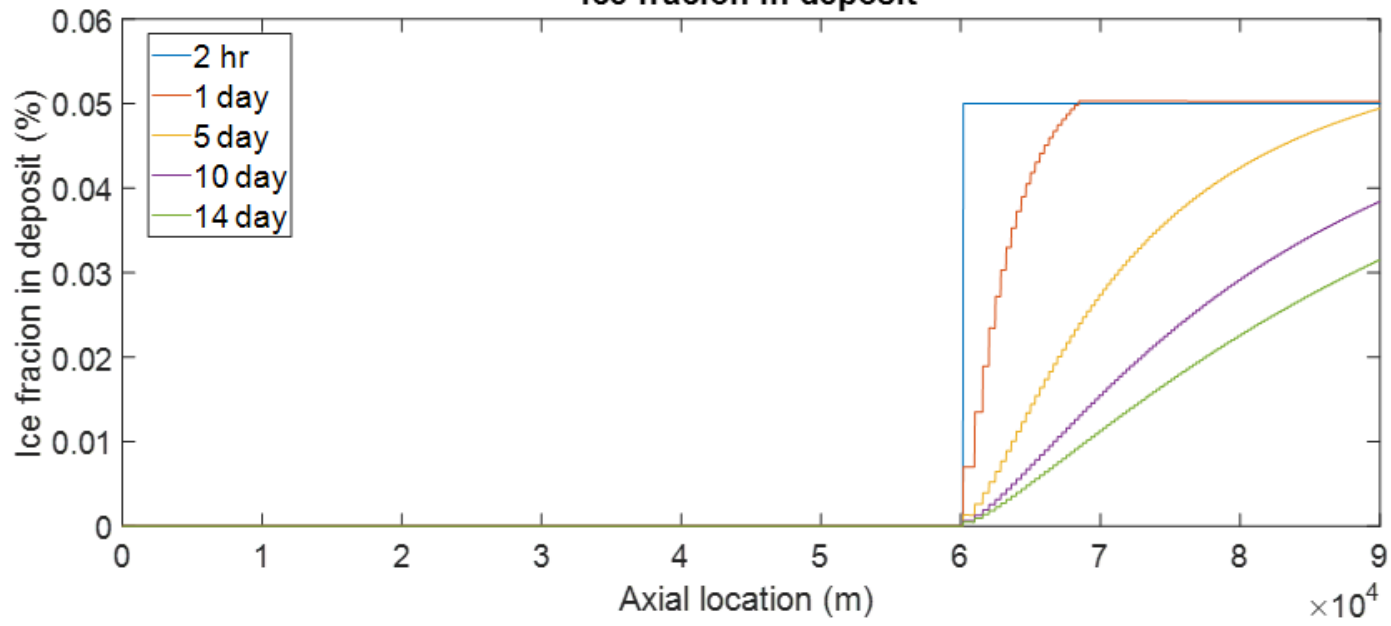

Figure 12: Prediction of the total solid fraction, wax fraction and ice fraction along the pipe at 2 hours, 1 day, 5 days, 10 days and 14 days

\section{Conclusions}

In this study, we developed a model base on molecular diffusion to predict wax, ice and wax-ice deposition in a pipeline with ambient temperature below water freezing point. Use three case studies, it was found that wax deposition rate is faster than ice depsoiton rate, due to the larger wax 
concentractio and concentraction gradient in wax deposition case. In addition, the coexistence of wax and ice deposition can lead to a more complicated deposition profile. In addition to section with only wax deposition zone, the depsotion zone mixed with wax and ice shows a competition between wax and water diffuiosn in the deposit, which slows down the solid fraction increase in the deposit. In the meanwhile, due to the decreasing internal diffusion rate, the total growth rate increases, which lead to a higher depsotion thickness than the cases with only wax or ice deposition.

\section{References}

Aiyejina, A., Chakrabarti, D. P., Pilgrim, A., \& Sastry, M. (2011). Wax formation in oil pipelines: A critical review. International journal of multiphase flow, 37(7), 671-694.

Alyeska Low Flow Impact Study Team. (2011, 15 June 2011). Low Flow Impact Study FINAL REPORT. Retrieved from http://www.alyeskapipe.com/assets/uploads/pagestructure/TAPS_Operations_LowFlow/editor_uploads/LoFI S_Summary_Report_P6\%2027_FullReport.pdf

Aris, R. (1985). On the permeability of membranes with parallel, but interconnected, pathways. Mathematical biosciences, 77(1-2), 5-16.

Burger, E., Perkins, T., \& Striegler, J. (1981). Studies of wax deposition in the trans Alaska pipeline. Journal of Petroleum Technology, 33(06), 1,075-071,086.

Chhabra, R. P., \& Richardson, J. F. (2011). Non-Newtonian flow and applied rheology: engineering applications: Butterworth-Heinemann.

Comfort, G., Dinovitzer, A., Lazor, R., \& Hinnah, D. (2008). Offshore arctic pipeline oil spill risk assessment. Paper presented at the 2004 international pipeline conference.

Cooper, W. A., Sand, W. R., Veal, D., \& Politovich, M. (1984). Effects of icing on performance of a research airplane. Journal of Aircraft, 21(9), 708-715.

Deen, W. M. (1998). Analysis of transport phenomena (Vol. 2): Oxford University Press New York.

DeMott, P. J., Finnegan, W. G., \& Grant, L. O. (1983). An application of chemical kinetic theory and methodology to characterize the ice nucleating properties of aerosols used for weather modification. Journal of Climate and Applied Meteorology, 22(7), 1190-1203.

Driest, E. V. (1956). On turbulent flow near a wall. Journal of the aeronautical sciences, 23(11), 1007-1011.

Gautier, D. L., Bird, K. J., Charpentier, R. R., Grantz, A., Houseknecht, D. W., Klett, T. R., . . . Schuenemeyer, J. H. (2009). Assessment of undiscovered oil and gas in the Arctic. Science, 324(5931), 1175-1179.

Grozdek, M., Khodabandeh, R., \& Lundqvist, P. (2009). Experimental investigation of ice slurry flow pressure drop in horizontal tubes. Experimental Thermal and Fluid Science, 33(2), 357-370.

Han, S., Huang, Z., Senra, M., Hoffmann, R., \& Fogler, H. S. (2010). Method to determine the wax solubility curve in crude oil from centrifugation and high temperature gas chromatography measurements. Energy \& Fuels, 24(3), 1753-1761.

Huang, Z., Lee, H. S., Senra, M., \& Scott Fogler, H. (2011). A fundamental model of wax deposition in subsea oil pipelines. AIChE Journal, 57(11), 2955-2964. 
Johnstone, R. L. (2014). Offshore oil and gas development in the Arctic under international law: risk and responsibility: Martinus Nijhoff Publishers.

Kaiser, B. A., Fernandez, L. M., \& Vestergaard, N. (2016). The future of the marine Arctic: Environmental and resource economic development issues. The Polar Journal, 6(1), 152168.

Khan, F., Ahmed, S., Yang, M., Hashemi, S. J., Caines, S., Rathnayaka, S., \& Oldford, D. (2015). Safety challenges in harsh environments: Lessons learned. Process Safety Progress, 34(2), 191-195.

Kim, C. K., Stuefer, M., Schmitt, C. G., Heymsfield, A., \& Thompson, G. (2014). Numerical modeling of ice fog in interior Alaska using the weather research and forecasting model. Pure and Applied Geophysics, 171(8), 1963-1982.

Li, W., Yu, B., Wang, X., Wang, P., \& Sun, S. (2012). A finite volume method for cylindrical heat conduction problems based on local analytical solution. International Journal of Heat and Mass Transfer, 55(21-22), 5570-5582.

Messinger, B. L. (1953). Equilibrium temperature of an unheated icing surface as a function of air speed. Journal of the aeronautical sciences, 20(1), 29-42.

Myers, T. G., \& Charpin, J. P. (2004). A mathematical model for atmospheric ice accretion and water flow on a cold surface. International Journal of Heat and Mass Transfer, 47(25), 5483-5500.

Niezgoda-Żelasko, B., \& Zalewski, W. (2006a). Momentum transfer of ice slurry flows in tubes, experimental investigations. International journal of refrigeration, 29(3), 418-428.

Niezgoda-Żelasko, B., \& Zalewski, W. (2006b). Momentum transfer of ice slurry flows in tubes, modeling. International journal of refrigeration, 29(3), 429-436.

Pletcher, R. H., Tannehill, J. C., \& Anderson, D. (2012). Computational fluid mechanics and heat transfer: CRC press.

Singh, P., Fogler, H. S., \& Nagarajan, N. (1999). Prediction of the wax content of the incipient wax-oil gel in a pipeline: an application of the controlled-stress rheometer. Journal of Rheology, 43(6), 1437-1459.

Sunne, S. (2015). Ice may delay restart of pipeline's breached Montana section. Retrieved from http://www.reuters.com/article/us-bridgerpipeline-oilspill-idUSKBN0KS1VE20150120

Walker, M. (2002). The science of weather: What's the difference between 'rime', 'glaze' and 'hoar frost'? Weather, 57(4), 143-143.

Xu, H., Bbosa, B., Pereyra, E., Volk, M., \& Mannan, M. S. (2018). Oil transportation in pipelines with the existence of ice. Journal of Loss Prevention in the Process Industries, $56,137-146$. 